\title{
EFFECT OF MAGNESIUM SUPPLEMENTATION ON PLASMA GLUCOSE IN PATIENTS WITH DIABETES MELLITUS
}

\author{
MELUDU S. C $^{1^{*}}$ AND ADENIYI F. A. A ${ }^{2}$ \\ ${ }^{1}$ Diabetology Unit, Department Of Medicine, University Hospital, University Of Liege, Belgium \\ ${ }^{2}$ Department of Chemical Pathology, College of Medicine, University of Ibadan. Ibadan, Nigeria
}

\begin{abstract}
Magnesium depletion and/or deficiency are known feature of diabetes mellitus, and could lead to increased insulin resistance and diabetic complications. This study therefore looked at the potential benefit of magnesium administration on the management of diabetic mellitus. Twelve apparently healthy and 6 non-insulin dependent diabetic (NIDDM) subjects received $15 \mathrm{mmol}$ (360 mg) elemental magnesium as NUG2 (Meram Laboratories, France) in $500 \mathrm{ml}$ of $0.9 \%$ saline intravenously over four hours. Blood samples were collected at baseline and at hourly intervals. The diabetic subjects had lower ionized $(0.41 \pm 0.03$ vs $0.48 \pm 0.01$ mmolAL; $P<0.05)$ and total $(0.73 \pm 0.04$ vs $0.88 \pm 0.02 \mathrm{mmol} / \mathrm{L} ; P<0.05)$ plasma magnesium concentrations than the non-diabetic subjects, reflecting a depletion of body magnesium. The administration of magnesium led to a significant increase in ionized and total plasma magnesium in both non-diabetic and diabetic subjects. Similarly, plasma glucose and insulin were significantly decreased, and homeostasis model assessment showed an increase in insulin sensitivity in diabetic subjects. In established cases of magnesium depletion and/or deficiency in diabetes mellitus, magnesium supplementation could be of great benefit in diabetic management.
\end{abstract}

Key words: Magnesium depletion-Magnesium administration-Diabetes mellitus-Insulin resistance.

*Address for correspondence: Dr S.C. Meludu is presently at the Department of Human Biochemistry, College of Health Sciences, Nnamdi Azikiwe University, P.M.B. 5001, Nnewi, Anambra State, Nigeria

\section{INTRODUCTION,}

Magnesium is an essential element in the mechanism of glucose transport across the cell membrane (Aikawa, 198 1; Goldman and Fisher, 1984), and various enzymes, important in carbohydrate oxidation require magnesium as a cofactor (Lehninger, 1950). Tissue magnesium deficiency/depletion and clinical manifestations of the deficiency can be present despite normal or borderline serum/plasma concentration (Zaloga, 1989).

In diabetes mellitus, magnesium depletion is a common occurrence (Speich et al, 1992; Schnack et al, 1992; Resnick et al, 1993), and it has been reported to exacerbate/contribute to reduced insulin sensitivity (Durlach and Rassiguier, 1983; Legrand et al, 1987) in non-insulin dependent diabetes mellitus. Magnesium administration was shown to increase plasma and erythrocyte magnesium levels and improve insulin response and action (Sjogren et al, 1988; Paolisso et al, 1992), due to an increased affinity of insulin to its receptors (Ishii, 1989). Therefore, magnesium administration/supplementation could prove to be beneficial in the management of diabetics. This study essentially focused on the effects of magnesium administration on glucose metabolism and insulin sensitivity.

\section{MATERIALS AND METHODS}

Twelve apparently healthy ( 9 males and 3 females) nonobese, and 6 NIDDM (3 males and 3 females) participated in the study. The non-diabetic subjects were aged, $28.8 \pm 1.7$ years, with BMT of $23.7 \pm 0.9 \mathrm{~kg} / \mathrm{m}$. Diabetic subjects were aged $47.7 \pm 2.7$ years with BMT of $24.6 \pm 1.6 \mathrm{~kg} / \mathrm{m}$ and glycosylated hemoglobin of $7.0 \pm$ $0.4 \%$. The study was carried out in diabetology unit, department of Medicine, University Hospital, University of Liege, Belgium.
$15 \mathrm{mmol}(360 \mathrm{mg})$ of elemental magnesium in 500 $\mathrm{ml}$ of $0.9 \%$ saline was given as an intravenous infusion over $4 \mathrm{hrs}$ at a rate of $125 \mathrm{ml} / \mathrm{hr}$ with an IMED pump (IMED Co., San Diego, Calif.). Blood samples were collected under vacuum with an indwelling catheter at 0 , $60,120,180$ and 240 minutes. Ionized and total plasma magnesium, plasma glucose and insulin were determined. On the day of the study, diabetic subjects were not allowed to take drugs.

The ionized plasma magnesium was determined by ion selective electrode (NOVA 8, NOVA Biomedicals, USA), total plasma magnesium determined by atomic absorption spectrometry (Perkin-Elmer Atomic Absorption Spectrometer 403/242). Plasma glucose concentration was determined with the use of AU 5000 Olympus Auto analyzer system, whereas plasma insulin concentration was determined by radio-immunoassay method. Percentage insulin sensitivity was calculated with Homeostasis Model Assessment (HOMA) computer program (Diabetes Research Laboratory, Radcliffe Infirmary, UK). The results are presented as mean \pm SEM.

\section{RESULTS.}

Diabetic subjects were older than non-diabetics (47.7 \pm 2.7 vs $28.8 \pm 1.7$ yrs; $P<0.05$ ), but their body mass indexes were similar $\left(24.6 \pm 1.1 .6\right.$ vs $\left.23.7+0.9 \mathrm{~kg} / \mathrm{m}^{2}\right)$. The pre-infused values of ionized and total plasma magnesium were lower in diabetics than in non-diabetics (Fig 1). On the other hand, the fasting plasma glucose and insulin concentrations were higher in diabetics compared with non-diabetics (Fig 1). lonized and total plasma magnesium concentrations increased in both diabetic and non-diabetic subjects throughout the period of magnesium infusion (Fig 1). Plasma glucose concentration in diabetics decreased significantly all through the period of magnesium administration, 
whereas the decrease was only significant in nondiabetics after 240 minutes (Fig 1). Plasma insulin also decreased significantly in diabetics from 120 minutes through 240 minutes and in non-diabetics throughout the period of magnesium infusion. Whereas plasma glucose concentration was higher in diabetics than in nondiabetics at all sampling time, plasma insulin was similar in the two group of subjects, except at 60 minutes when if was higher in diabetics.

\section{DISCUSSION}

Diabetes mellitus or more specifically hyperglycemia with glycosuria appears to induce magnesium depletion both directly via osmotic diuresis and indirectly by its effects on vitamins, ions and protein (Sjogren et al, 1986; Campbell, 1987). In humans, sugar loading had been shown to cause magnesuresis and could result in intracellular magnesium depletion.

In this study, diabetics had a significant decrease in both ionized and total plasma magnesium concentrations compared with non-diabetics as previously reported (Resnick et al, 1993; Meludu et al, 1994). The depletion in ionized magnesium concentration, which is the physiologically active form of magnesium and readily exchangeable (Reinhart, 1990;
Reinhart, 1991) does suggest whole body magnesium depletion (intracellular and extracellular).

lonized and total plasma magnesium concentrations increased significantly following intravenous administration of magnesium in both diabetic and non-diabetic subjects. Interestingly, ionized plasma magnesium concentration only differed significantly after the first 60 minutes in the two groups of subjects, because of the initial difference in the preinfused magnesium concentration. In fact, ionized magnesium easily equilibrates with other compartments and it reflects the immediate changes that occur following magnesium administration.

Plasma glucose concentration in both diabetic and non-diabetic subjects was decreased following magnesium administration. In normal subjects, glucose homeostasis in fasting state is maintained constant by control of hepatic glucose output, with the rate of entry of glucose into circulation approximating the rate of removal (Dinnen et al, 1992). The decrease in plasma glucose could therefore be attributed to the direct effect of magnesium on glucose disposal, since magnesium is important for the action of the rate limiting enzymes of glycolysis (Altura, 1982).

Fig 1.

Ionized and total plasma magnesium, plasma glucose and insulir\# concentrations during intravenous magnesium administration to diabetics (open squares) and normal subjects (closed circles). $+\mathrm{P}<0.05$ between diabetic and nonnal subjects, $\mathrm{P}<0.05$ within diabetics, \# P< 0.05 within normal subjects, 
Plasma insulin concentration was also decreased following magnesium administration to diabetic and nondiabetic subjects. Analysis by Homeostasis Model Assessment (HOMA) computer program showed a significant increase in percent insulin sensitivity, even though to a lesser extent in diabetics (data not shown). Interestingly, percent B-cell response was decreased in non-diabetics, whereas it was not affected in diabetic subjects. The overall effect of magnesium administration on plasma glucose and insulin is therefore on the increase in glucose disposal as a result of an increase in insulin activity (Paolisso et al, 1992). In effect, hypermagnesemia inhibits insulin secretion (Zofkova et al, 1988), while it enhances insulin sensitivity through increase in binding affinity of insulin to its receptors (Yajnlk et al, 1984; Paolisso et al, 1992).

In conclusion, magnesium administration/ supplementation as an additi6iial means of diabetic patient management will enhance glucose oxidation and restore the magnesium losses.

\section{Acknowledgement}

Our profound thanks to Prof P. J. Lefebvre and his team at the Department of Medicine, Un -ivers ity of Leige, Belgium for all their support to M. S. C.

\section{REFERENCES}

Aikawa, J. K. (1981). Magnesium: Its biological significance. Boca Raton,Fla,CRC Press Inc.

Altura, B. M. (1982). Magnesium and. regulation of contractility of vascular smooth muscle. Adv. Mcrocirc. 11, 77113.

Campbell, R. K. (1987), Magnesium and diabetes: a clinical concern? Prac. Diabetol. May/June, 8-9.

Dinnen, S., Gen'ch, J. and Rizza. R. (1992). Carbohydrate metabolism in non-insulin dependent diabetes mellitus. $\mathrm{N}$. Engl. J. Med. 327, 707-713.

Durlach, J. and Rassiguier, Y. (1983). Magnesium et glucides 1. Donnes cliniques et therapeutiques. Magnesium. 2,192-224.

Goldman, J. and Fisher, V. (1984). Magnesium is required in addition to calcium for insulin stimulation of glucose transport. In: The Endocrine Society; abstract of $65 \mathrm{lb}$ annual meeting, San Antonio, Texas, 1983. Baltimore, Md; Endocrine Society. 271.

Ishii, T. (I 989). Effect of magnesium on the action of insulin during glucose metabolism. J. Osaka City Med. Center. 38, 675-689.
Legrand, C., Okitolonda, W., Potter, A. M., Lederer, J. and Henquin, J. C (1987). Glucose homeosrtasis in magnesium deficient rats. Metabolism. 36, 160-164.

Lehninger, A. S. (I 950). Role of metal ions in enzyme systems. Physiol. Rev. 30, 393429.

Meludu, S. C., Castillo, M. J., Scheen, A. J., and Lefebvre, P. J. (1994). Decrease plasma ionized magnesium levels in type I and type 2 diabetic patients. NUgnesium Res. 7 (supple 1), 23-24.

Paolisso, G., Sgambato, S., Gambardella, A., Pizza, G., Tesauro, P., Varricchlo, M. and D'Onofrio, F. (1992). Daily magnesium supplements improve glucose handling in elderly subjects. Am. J. Clin. Nutr. 55, 1161-7.

Reinhat R. A. (1990). Magnesium metabolism. Wisconsin Med. J. Oct, 579-583.

Reinhart, R. A. (1991). Clinical correlates of the molecular and cellular actions of magnesium on the cardiovascular systems. Am. Heart J. 121, 1513-1521.

Resnick, L. M., Barbagallo, M., Gupta, R. K. and Laragh, J. H. (1993). Ionic basis of hypertension in diabetes mellitus: Role of hyperglycemia. Am. J. Hypertens. 6, 413-417.

Schnack, Ch., Bauer, I., Pregant, P., Hopmeier, P. and Schemthaner, G. (1992). Hypomagnesemia in type 2 (noninsulin-dependent) diabetes mellitus is not corrected by improvement of long-term metabolic control. Diabetologia. 35 , 77-79.

Sjogren, A., Floren, C. H. and Nilssson, A. (1986). Magnesium deficiency in IDDM related to level of glycosylated hemoglobin. Diabetes. 35, 459-463.

Sjogren, A., Floren, C. H. and Nilsson, A. (1988). Oral administration of magnesium hydroxide to subjects with insulindependent diabetes mellitus: effects on magnesium and potassium levels and on insulin requirement. Magnesium. 7, 117-122.

Speich, M., Murat, A., Auget, J. L., Bousquet, B. and Amaud, P. (1992). Magnesium, total calcium, phosphorous, copper and zinc in plasma and erythrocyte of venous cord blood from infants of diabetic mothers, comparison with a reference group by logistic discriminant analysis. Clin. Chem. 3 8, 2002-2007.

Yajnlk, C. S., Smith, R. F., Hockaday, T. D. R. and Ward, N. 1. (1984). Fasting plasma magnesium concentrations and glucose disposal in diabetes. Br. Med. J. 28 8, 1032-1034.

Zaloga, G. P. (1989). Interpretation of the serum magnesium levels. Chest. 95, 257-8.

Zofkova, I., Zamrazil, V. and Simeckova, A. (1988). Acute hypennagnesemia retards glucose assimilation and inhibit insulin secretion during intravenous glucose tolerance test (IVGTT). Horm. Metab. Res. 20,120-121.

Received: December 2000

Accepted: June 2001 